\title{
Study on the Construction of Gu Cheng's Isolated City Field
}

\author{
Tingting Zhou
}

\author{
College of Arts, Jiangxi Normal University, Nanchang City, China
}

\begin{abstract}
Gucheng Life with poetry for life. He is the main representative of "Misty poetry" and the only fairy poet in China. Jiangxi Normal University students in 2018 year 8 months in Guangdong Meizhou held a "Gucheng Gu City Vision" of the symposium, the meeting belongs to the exchange between student's discussion, a small group will. Gucheng's poems and Gucheng's "death" have been the subject of discussion among many scholars and experts over the years, thus establishing the theme of this conference--the Gu City vision of Gucheng. This article from the speech, the sentiment, the meaning three aspects to Gucheng "the Gu City field of vision" launches the discussion exploration, is also to this group meeting summary.
\end{abstract}

Keywords: Gucheng; gu-city words; love; sense.

\section{Introduction}

"The Dark Night gave me black eyes, but I used it to look for the light!" "Gucheng's poetry," a generation of people have been circulating so far, many people still remember the pair of black eyes, in the dark looking for the light, but in that era, can give understanding and into their own motivation, how many people can? Even if the gucheng himself, although he said "look forward to a kind of eternal, even if the scars, but also desperate", he himself has not been able to completely from his solitary town out. When it comes to Gucheng's "Gu City Vision", students from three aspects of the interpretation: words, feelings, meaning. A prophet is a poet, a Gucheng a word, more words in poetry, poetry is his psychological feelings of sustenance, love, love in the life, because of feelings and happiness, because of feelings and loneliness, but also because of feelings and melancholy tactfully, the meaning of the realm, this is exclusive to the Gucheng Gu City realm.

\section{Words-Poetry in Words, Words in Poetry}

Gucheng from an early age to the poetry, in his own words, from nature. 1969 years Gucheng left Beijing to the countryside, the natural pristine desolation did not let the young poets feel frustrated. There was "only a vast expanse of desolate white alkaline areas, and there was not much grass." I am in the middle of Heaven and earth, feeling is not before the ancients, no one, nothing, heaven and earth between me. [1] at this time, the young poet Gu City sensitive to find his "gu City", this city, nothing, only his own. Of course, in his view, any change originating from nature is a natural "voice", which is written to "answer what Nature says to me."

He immersed his heart in poetry and responded to nature with poetry.A seed, can also respond to nature, "the seeds in the frozen Earth dream of Spring"; a flower seed, in the spring home will also get "green jacket" and "color lace cloth hat"; "All the early girls / All the little girl will go to the fields / to pick up the spring / Red cherry / and Smile "and for Gucheng himself," I will breathe like grass / whisper my dream to spring. " Spring in Gucheng "fairy tale World" in the host of the nature of all the dreams and life wishes, he also in the heart to build his ideal kingdom. But this kingdom, is undoubtedly a "gu City", "This land / Morning road / overgrown with ferocious shrubs." Gucheng's appreciation of nature is essentially an experience of self-life,[2] He not only loves nature, He also raised nature to the height of philosophy, and named "Philosophy of Nature", in the "no purpose of me-the outline of natural philosophy" he explained: "Man and nature is a whole, human life is from nature, death and return to nature, sang sang tightly are in the arms of nature, Consistent with the eternal laws of nature. "[3]

Gucheng said: "For a man, it is not to be free in nature." "[4] The freedom of the body is often not free, and the limitation of the mind is the true bondage." It can be said that his pursuit of fantasy as a naïve child, but his cold view of the world and as the thinker generally sober. As early as in 1979 's 
dream of seeds, he realized that the dream of the spring will never come true. "Seed, in the frozen Earth Dream Spring / Its head is covered with a huge slate." "1982," he wrote in one of my springs, "the wooden window / flat my farmland / My little yak / my single plow. I have to work, to choose the seeds of the dream / Let them shine in the palm and all scattered in the water. "[5]

Fantasy and the real world there is a huge difference in childhood, that spring to the arrival of the sense of life to wake up simple feelings can only recall but cannot be obtained again. [6]

\section{Love-Love and Affection}

"Cut the Moon / be hidden by God in the thick curtain / All is Over",1993 8 Days is a special day, is also the end of all the days. There are divergent opinions about the departure of Gucheng. Some say he's been wandering overseas for years, tired of want to return to live long, and his wife Cheille but want to stay abroad, the couple constantly conflict, in the loss of reason, Gucheng raised the axe; another argument is Gucheng in Germany, a German Chinese frantically pursue Gucheng's wife Cheille, noisy, The man was caught up in New Zealand, and Gucheng was never tolerated, and there were unfortunate incidents, and others said Gucheng was mentally ill, and he had an axe complex. Either way, it seems to me that nothing is intrinsic or extrinsic, and it is also a cultural imbalance. 1987 Years later, there are a few poets have chosen to leave, from Chite to Schming is, from 1989 years in Shanhaiguan rails suicide to 1991 years in Beijing, GE Wheat to cast water, we can find the psychological locus of the poet in the age of the century.

Gucheng, the Gu city, confuses the ideal with the reality, and confuses love and affection. His ideal Pure Land is the daughter country, he in to Wenxin's letter said: "I was in the Dream a daughter world" The girl is touched, my heart will tremble, because it is my heart. "Where is this piece of pure land to look for?" Eventually he found it in New Zealand's Rapids Island, Gu City himself, looking for wood and food, mending houses, digging septic tanks. He said, "I will build a city and shut the world out." "He understands reality, understands reality, but he just does not want to face the reality, assumes the adult responsibility." He did not want to become a father, do not allow his son little fungus in the side, his heart child can only be his own. "I am a child, a spoiled child by a fancied mother. "I am a sad child, and never grow up. "In1982 years, he still borrowed a child's distrust of adults," wrote: "In the Dream / My hair white / I reached the age of 50 / Read the whole world / I know all about you /. You / have nothing to do.

For Gucheng, the game of life is only a lower level of his children's world, his highest ideal is to build a heavenly garden. As he said, "want to earn a White House".

\section{Sense-to do, to the End}

In the 1992 interview, Gucheng divided itself into four stages, namely the natural phase (19691974) Culture Stage (1977-1982 Anti-culture stage (1982-1986) Without Me (1986 years later) Gucheng said: "In the absence of me, I have lost interest in culture and anti-culture, abandoned the search for ' I ', and entered the ' Without me ', I began to do a natural poem, no longer using word skills, and no longer express myself. I no longer have dreams, no hope, no fear. "[7] Xu He imprisoned in the solitary city too long, his poetry is also full of the secret words, verses violate common sense, difficult obscure, Become hopeless and hopeless. $1988 \mathrm{He}$ wrote in the tomb-bed: "I know Yong is coming, not sad / The pine trees have my wish. The person who has done, the world is very long / I should rest / walk through the People say the branch is low / walked people said the branch is very long. His final choice is the result of his idealism encountering individual's death instinct, destruction consciousness and life value pursuit lost.

As early as he was very young, he realized "death". Gucheng 1989 12th at the Chinese University of Hong Kong "resume life", said: "At the age of five, once I was a person in the house, I noticed the white wall, I feel very beautiful, I fell asleep." When I wake up. I looked at the white wall, the heart suddenly has a feeling of emptiness, as if the first clear know I was dying, the first time I saw death so close to me. [8] 
In exploring the relationship between literature and suicide, Alvare has put forward two types of suicide, one is "totalitarian artist", which means that the artist finally chooses suicide because of the inhuman repressed external social system, and the other type is "extremist artist", which refers to an artist with intrinsic self-destruction. Gucheng should be the combination of these two types, with Freud's point of view, when the instinct to overcome the "ego", the behavior of the person is a certain destructive. Gucheng hopes that his spirit is in a free space, that "a kind of inner contradiction and a demand for unification" of this contradictory instinct "prompted him to seek me". [9]

Guo in "Gucheng and Poetry" recalls: "In the ' Cultural Revolution ' in the early days, someone in our downstairs road opposite the wall, brush two large slogans, I do not know is affixed to the wrong, or paste a mistake, is immediately surrounded by a large number of passers-by, tightly entangled, grabbed, press the head, kicking with the foot. Gucheng at first stared through the cracks in the window, and later he was terrified and pale. He closed the window, curled up in the bed, like a snail, never to look out the window more. He is increasingly trying to avoid people, to avoid the eyes, to avoid the noise, agitation of the voice, just want to go there is no one only in the world of nature. [10] Gucheng hid in his gu city: "I wish to rest here / in the midst of flowers and fog / I will find a new / lost feeling in my childhood."

My heart / is a city. cheerless / cheerless

My dream / is a city. Quiet / quiet

A Gucheng, a Gu city. Schopenhauer says that death is the time to break free from the shackles of the original and to regain freedom, but where is the freedom belonging to Gucheng. He remained, after all, in his Gu city.

\section{References}

[1]. Gucheng. from self to Nature [G]// Anthology of Gucheng. bie you tiandi. Harbin: Northern Literary Publishing house, 2005:99.

[2]. Xu Yan. Gucheng's sense of death [J]. Journal of Henan University of Science and Technology, 2003,21, (3).

[3]. Gucheng. full compilation of Gucheng poems [M]. Shanghai: Sanlian, 1995.

[4]. Gucheng. build a small town [G]// Anthology of Gucheng. Vol. Bie you tiandi. Harbin: Northern Literature and Art publishing house, 2005:229.

[5]. Gucheng. from self to Nature [G]// Anthology of Gucheng. bie you tiandi. Harbin: Northern Literary Publishing house, 2005:99.

[6]. Gucheng. full compilation of Gucheng poems [M]. Shanghai: Sanlian, 1995.

[7]. Tangxiaodu. the death of Gucheng [J]. contemporary writer commentary, 2005:19.

[8]. Gucheng. Selected selections of Gucheng (vol. i). Bie you Tiandi [M]. Harbin: Northern Literature and Art publishing house, 2005:35.

[9]. Gucheng. Selected selections of Gucheng (vol. i). Bie you Tiandi [M]. Harbin: Northern Literature and Art publishing house, 2005:232.

[10]. Guo. Gucheng and poems [A]. Gucheng. Gucheng' s poems [M]. Beijing: People's Literature publishing house, 2005. 